\title{
10 Years of the Plasmonics Journal
}

\author{
Chris D. Geddes ${ }^{1}$
}

Published online: 27 February 2016

(C) Springer Science+Business Media New York 2016

March 2016 marks the 10th anniversary of the founding of the Plasmonics Journal. Over this last decade, the journal has earned a well-deserved international reputation for being both the first ever and most prominent solely Plasmonics-based journal in the world today.

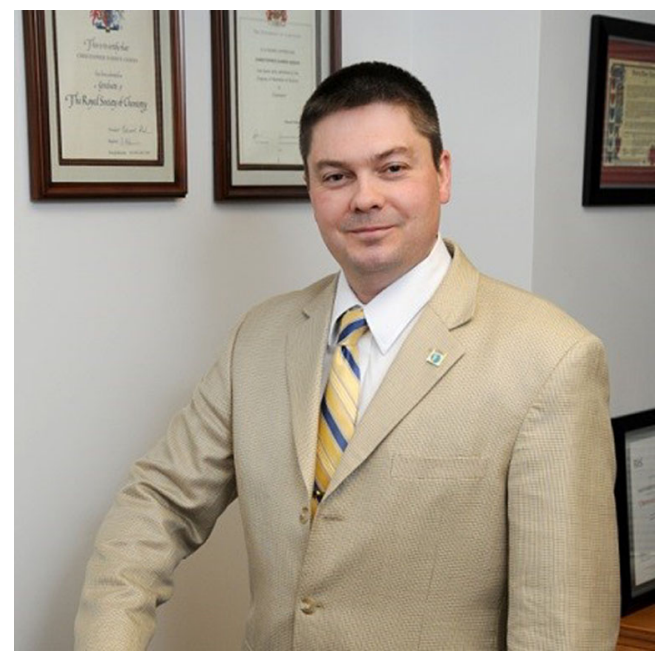

Since 2006, the journal has published 1164 articles which have been cited some 7431 times. The most cited article today is "Review of some interesting surface plasmon resonanceenhanced properties of noble metal nanoparticles and their applications to biosystems" which was published in 2007 and has been cited some 424 times. Since 2006, there has been

Chris D. Geddes

geddes@umbc.edu

1 Institute of Fluorescence, University of Maryland Baltimore County, Columbus Center, 701 East Pratt St., Baltimore, MD 21202, USA
424,000 article downloads from the Springer Plasmonics website, with 28 open access articles published. During the last 10 years, the impact factor has fluctuated between 2 and 5 , and currently sits at 2.238 . There have also been numerous thematic issues in the Plasmonics Journal.

I had the idea for a new solely Plasmonics-based journal in the early 2000s, an idea fueled because most of my own research was fluorescence-based plasmonics, and there were simply not that many journals at the time which were suitable for this content, although this has changed significantly today. In the early 2000s, Applied Physics Letters and the Journal of Physical Chemistry B as well as a few others published Plasmonics-based articles, but the journals were not solely Plasmonics-based, and the editorial boards of these journals were stretched in reviewing the latest Plasmonics concepts. Subsequently, the idea of the Plasmonics Journal was born. I remember flying to San Diego in California in the early 2000s to meet the Springer editors, in particular Aaron Johnson, whom were all attending the Annual BioPhysical Society meeting at the conference center there, where I pitched the "Plasmonics Journal" concept to them. It was a cool day in San Diego as I thumbed through powerpoint slides on my laptop at an outside hotel café, the Springer folk listening carefully trying to decide if my enthusiasm for a new area of science "Plasmonics" was warranted, or would Plasmonics just be a passing concept, here today gone in a few years' time. While I was completely sold on the concept, I had no idea how receptive Springer would be to the launching of a new journal; after all, launching a journal is a notable financial commitment for any publisher. Within an hour, we got the green light to move forward, providing the upper Springer management approved, which they did within days. I subsequently spent the next few months recruiting an editorial board, outlining the scope of the journal, and preparing to make "Plasmonics" an all-electronic journal from the 
beginning, noting that main stream scientific publishing took many years to transition to e-based reviewing and publishing, i.e., the system we have today. Subsequently, we started both inviting and reviewing content in 2005, with the first issue published in March 2006. Ten years later, the Plasmonics Journal is a thriving journal and a huge success, publishing timely, excellent content, highly-cited articles from around the world.

At this time, I would like to thank the authors for their excellent Plasmonics-content over the years, both the reviewers and editorial board for both reviewing and coordinating reviews respectively, and in particular, I would like to thank the Springer editors, who shared my vision 12 years or so ago, when Plasmonics as a scientific discipline was just emerging into the main stream scientific arena; I thank you all.

Best

Dr Chris D. Geddes

Professor

Founding Editor-in-Chief: Plasmonics

Maryland, February 16th 2016. 